\title{
Responsabilidade social dos cientistas Natureza das ciências exatas
}

\author{
Samuel Macdowell
}

As ciências da natureza e, particularmente, as ciências exatas começaram a adquirir características próprias, que as diferenciam da filosofia, das humanidades e hoje tambem das ciências sociais, a partir do século XVII, devido, principalmente, à influência de Galileu e de Newton e de suas posições em defesa de um pensamento científico independente e de uma metodologia própria.

Em virtude destas características e do rápido desenvolvimento que tiveram, as ciências passaram a ocupar uma posição importante e, em certas épocas e circunstâncias, por vezes central na construção da sociedade e na evolução da cultura e do pensamento.

Não pretendo focalizar, em maior profundidade, a história do desenvolvimento da ciência e do pensamento científico; limitar-me-ei a apontar algumas das características que marcaram, desde o início, a concepção que tinham da nova ciência os próprios cientistas, sobretudo aqueles que mais contribuíram para sua construção.

As ciências exatas, isto é, as ciências físicas surgiram com base em precisas observações astronômicas de Ticho Brahe e da introdução, por Galileu, do método experimental como seu alicerce. Suas investigaçōes levaram à formulação do princípio da inércia como fundamento da cinemática. A filosofia natural, que as precedeu, procurava entender e explicar os fenômenos naturais de um modo essencialmente qualitativo.

Entretanto, utilizando as precisas medidas astronômicas de Ticho Brahe, Kepler descobre que os planetas movem-se em torno do Sol de acordo com certas leis que podem ser enunciadas rigorosamente em termos matemáticos. A partir de então, a descrição dos fenômenos naturais, pela nova ciência, toma um caráter quantitativo.

A primeira grande síntese da ciência física deve-se ao gênio incomparável de Isaac Newton (1642-1727) ${ }^{1}$, que formulou as leis gerais da mecânica ao mesmo tempo que descobria a grande lei da atração universal gravitacional, que explicam não apenas as leis de Kepler, mas também fenômenos aparentemente tão diversos como a queda dos corpos, o movimento do pêndulo, o movimento da Lua em torno da Terra e o fenômeno das marés.

Aqui ficam já esboçadas três características de metodologia das ciências exatas. Primeira: a observação do fenômeno e utilização do método experimental para medir grandezas que podem ser quantificadas. Segunda: a formulação de hipóteses, modelos, leis e, finalmente, teorias e princípios que interpretam os fenômenos naturais usando uma linguagem matemática precisa. Terceira: que das leis teóricas assim formuladas podem-se deduzir

1 É interessante notar que, no seu monumental tratado Philosophiae Naturalis Principia Matematica (1687), Newton descreve as leis da mecânica e do movimento, exclusivamente em termos geométricos, conhecidos na época, embora já houvesse criado o cálculo infinitesimal, utensílio mais apropriado para a formulação dessas leis. 
previsões a respeito de novos fenômenos que podem ser testadas por meio de medidas experimentais.

Portanto, a metodologia científica envolve, em geral, um ciclo que se inicia por observaçōes e medidas experimentais; estas conduzem à formulação de um modelo ou de uma teoria expressa em linguagem matemática, da qual podem-se extrair previsōes sobre novos fenômenos que, se confirmadas, justificam a validez da teoria (dentro de certos limites de aplicabilidade).

Por outro lado, os cientistas concebern as ciências da natureza como uma atividade intelectual cujo objetivo é descobrir e entender as leis que regem os fenômenos naturais. Ao contemplar a natureza, o cientista é movido pela curiosidade de desvendar seus segredos, usando, para isso, métodos experimentais engenhosos e muitas vezes originais e procurando entendê-los em termos genéricos, correlacionando, por meio de leis ou princípios gerais, fenômenos aparentemente bem diversos.

A ciência da natureza, a ciência pura, tem um valor intrínseco estético que deriva da própria descoberta e apreciação do fenômeno novo, das correlaçōes entre fenômenos analisados à luz de princípios simples e sintéticos.

A contribuição da ciência para a humanidade se situa primariamente no plano da cultura.

Os cientistas entendem que a ciência é universal e deve ser difundida sem preocupaçāo de fronteiras, de vantagens pessoais ou das instituições que a promovem. Os resultados das pesquisas científicas são publicados em revistas especializadas de livre circulação ou difundidos em congressos, freqüentemente de âmbito internacional, sobretudo na era moderna. As atas das academias de ciência, com transcrição dos trabalhos e comunicações submetidos em suas reuniōes, são tornadas públicas e podem ser livremente usadas por qualquer pesquisador.

Este caráter universal da ciência pura, os cientistas vêm, ao longo da história, esforçando-se zelosamente por preservar através de colaboração e intercâmbio internacional e da livre troca de informação científica.

Historicamente, as universidades, como centros de transmissão de conhecimentos, livre discussão e circulação de idéias e propagação da cultura, tornaram-se veículos por excelência das atividades científicas, proporcionando o ambiente e mentalidade necessários para o florescimento das ciências.

\section{Ciência e Tecnologia}

Além de sua contribuição à cultura, $o$ desenvolvimento científico propiciou importantes avanços tecnológicos, que tiveram profundas conseqüências $e$ repercussōes sociais e tambem um grande impacto na relação do homem com o meio ambiente.

Por tecnologia entendo, aqui, a atividade de criação dos meios de utilização de recursos naturais em proveito do homem e da sociedade.

Alguns importantes avanços tecnologicos resultaram de inventos e descobertas individuais isoladas, extremamente inteligentes $e$ engenhosas, não-relacionadas, diretamente, a um desenvolvimento científico. Entretanto, mais sistematicamente, os progressos da tecnologia são fruto da aplicação de conhecimentos científicos.

Embora distintas, principalmente quanto a seus objetivos, ciência e tecnologia estão estreitamente correlacionadas e cada vez mais interdependentes.

Este entrelaçamento entre ciência e tecnologia, não creio que seja meramente ocasional e acidental. A ciência, por sua natureza

experimental, necessita de aparelhos e instrumentos de medida cada vez mais sofisticados e precisos.

No passado, estes aparelhos e instrumentos eram freqüentemente inventados pelos próprios cientistas, cujo trabalho era predominantemente individual. Avanços e novas descobertas, na área experimental, freqüentemente resultaram da
Por tecnologia entendo, aqui, a atividade de criação dos meios de ntilização de recursos naturais em proveito do homem e da sociedade. 
introdução de novas técnicas de instrumentação e de medida. Estas técnicas, produzidas e testadas nos laboratórios de pesquisas científicas, são posteriormente utilizadas no desenvolvimento tecnológico. Por outro lado, avanços na tecnologia permitem a construção de aparelhagens científicas mais sofisticadas, com as quais novas fronteiras da ciência vão sendo abertas.

Citarei alguns exemplos através da história, que ilustram esta relação. A descoberta da máquina a vapor (Watts, 1779) teve como fundamento teórico a lei de Boyle-Mariotte de expansão dos gases. Ela precedeu o aparecimento da termodinâmica no início do século XIX, cujos princípios gerais foram formulados a partir da contribuição pioneira de Sadi Carnot, um engenheiro, e das pesquisas de Joule, demonstrando a equivalência entre quantidade de calor e trabalho mecânico. $O$ advento desta ciência serviu de base para inúmeras aplicações da máquina a vapor, que se tornou instrumento decisivo no desencadeamento da Revolução Industrial.

Os progressos na compreensão dos fenômenos eletromagnéticos, sobretudo devido à contribuição de Faraday (mas também de muitos outros como Coulomb, Volta, Ampère, Biot e Savart, Gauss etc.), e que culminaram com a completa formulação da teoria por James Clerk Maxwell, foram responsáveis pelo enorme avanço tecnológico que resultou da utilização da corrente elétrica e de campos magnéticos em geradores e motores elétricos, dínamos, alternadores, transformadores e pela emergência da energia elétrica com a construção das centrais elétricas e das linhas de transmissão.

Posteriormente, a descoberta das ondas hertzianas vinha confirmar a previsão da teoria de Maxwell e permitiu um novo meio de comunicação através da telegrafia e, com a invenção do diodo, da radiodifusão.
No início do século XX, ocorrem na física duas grandes revoluções que vão dominar a evolução desta ciência durante todo o século. A primeira, a Teoria da Relatividade, de Einstein, a Relatividade Especial (1905), que modifica os fundamentos da Mecânica Newtoniana e a própria noção de espaço e tempo, e a Relatividade Geral (1915), que reformula a Teoria da Gravitação, atribuindo-a a propriedades geométricas do espaço, adquiridas pela presença de matéria ou energia. A segunda, a Mecânica Quântica, de Heisemberg e Schrodinger (1910), que reinterpreta a mecânica em termos probabilísticos em contraposição ao determinismo da Mecânica Newtoniana (Princípio de incerteza, de Heisemberg). Em 1925, Dirac formula a Teoria Quântica do Elétron, prevendo a existência das antipartículas. Desenvolvem-se a física atômica e molecular, a mecânica estatística e a física do estado sólido e, a partir da Segunda Guerra Mundial, a eletrônica, a física nuclear, a ótica quântica, e a física das partículas elementares.

Algumas descobertas importantes tiveram enormes conseqüências para o progresso tecnológico:

supercondutividade, semicondutores, transistores, microondas, cavidades ressonantes, guias de ondas, lasers, ressonância nuclear magnética, fissão nuclear e fusão nuclear.

Uma nova ciência, a ciência da informática, é criada como fruto do avanço tecnológico na acumulação e processamento de informação em pastilhas semicondutoras de silício e na eletrônica dos circuitos integrados.

A física de partículas elementares segue uma direção que se distancia bastante da física experimental praticada nos laboratórios das universidades. Para investigar o substrato mais primitivo da matéria em domínios de dimensão cada vez menores torna-se necessário construir grandes aceleradores com diâmetro de vários quilômetros e capazes de acelerar partículas até energias cada vez mais altas, da ordem de bilhões e até um trilhão de Electron-Volts. 
Estes laboratórios não são mais construídos e manejados por um pequeno grupo de cientistas. Eles requerem um esforço nacional, com um orçamento enorme, de muitos milhões de dólares, e até mesmo de grandes colaboraçōes internacionais.

Sua construção é projetada por desenhistas e engenheiros especializados, e um corpo permanente de engenheiros e técnicos $e$ utilizado no seu funcionamento. $O$ Centre Européen pour la Recherche Nucleaire (CERN), que é hoje o maior laboratório de pesquisas em física de partículas elementares, mantém um corpo de técnicos e engenheiros de mais de 2 mil pessoas, o que é numericamente superior ao seu corpo científico. Uma experiência, cujo projeto e execução duram vários anos, envolve a colaboração de um número enorme de pesquisadores, mais de uma centena, provenientes de um grande número de laboratórios e centros de pesquisa de vários países.

Os objetivos primários desses grandes laboratórios permanecem orientados para a ciência pura e para a descoberta de novos fenômenos elementares na fronteira da física. Entretanto, não só a interdependência entre ciência e tecnologia torna-se cada vez mais estreita, mas também a canalização de recursos públicos para financiamento de tais projetos atinge proporçôes muito mais elevadas.

\section{Integração da Ciência no Bem Comum Social}

Em virtude da ligação cada vez maior entre progresso científico e desenvolvimento social, cabe aos cientistas indagar com mais freqüência e de modo mais crítico e sistemático sobre a utilização da ciência e dos resultados de suas pesquisas.

Creio que há evidência contundente em favor do argumento de que os investimentos públicos em pesquisa científica têm tido um retorno bastante compensador em termos da utilização para o bem-estar social dos progressos científicos obtidos. Por outro lado, creio também que se pode questionar, não somente quanto à aplicação de conhecimentos científicos com finalidades destrutivas ou nocivas à humanidade e à natureza, mas também quanto à distribuição destes benefícios entre diferentes setores da sociedade.

Considerarei aqui, em particular, quatro aspectos do relacionamento da ciência com a sociedade que, a meu ver, requerem a atenção e a reflexão do cientista:

1) Aplicação da ciência com fins militares;

2) Impacto do avanço tecnológico e industrial no meio ambiente;

3) Distribuição dos benefícios resultantes do progresso científico e tecnológico;

4) Difusão da ciência e o problema da educacão.

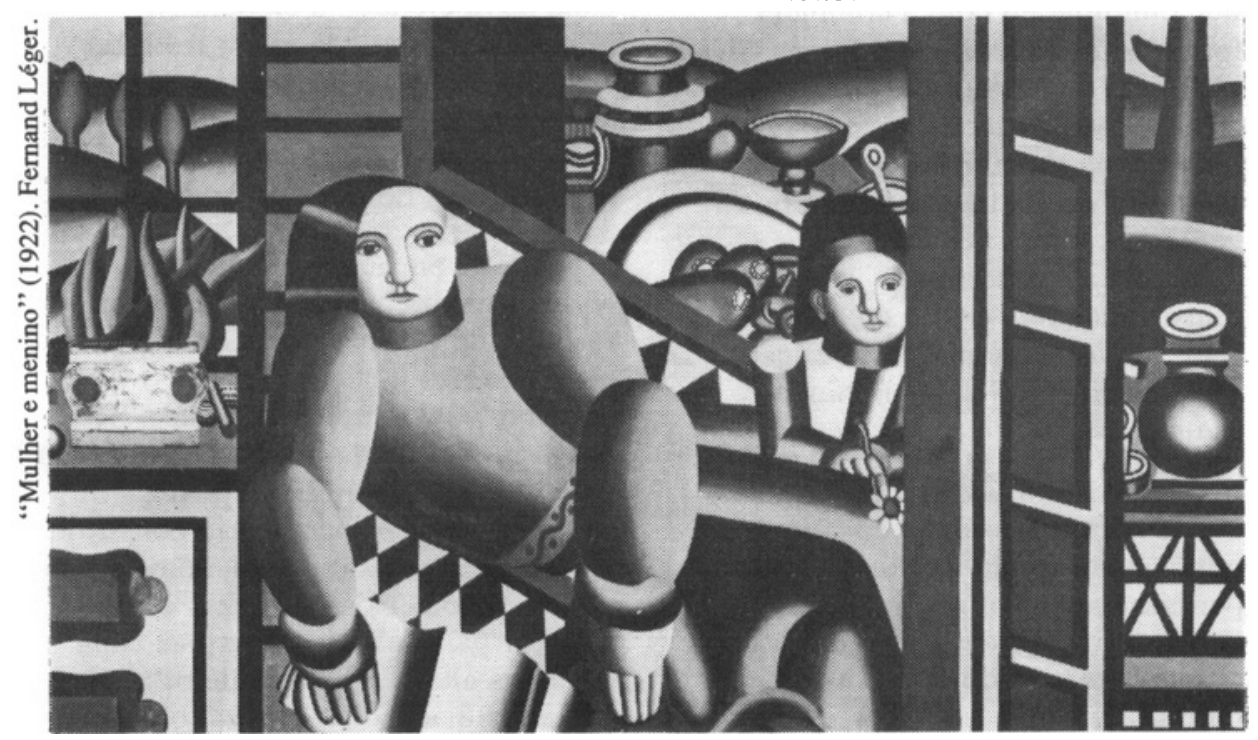




\section{Aplicação da ciência com fins militares}

Em todas as épocas da história da hum. nidade, grupos sociais utilizaram seus zonhecimentos e compreensão de fenômenos naturais com fins militares, para a construção de poderosas armas de guerra e artefatos de destruição.

Entretanto, a descoberta dos armamentos nucleares introduz uma mudança qualitativa no equacionamento do problema da convivência entre naçóes e da resoluçāo de conflitos pelas armas.

Isto porque, mesmo que o uso de bombas nucleares seja dirigido a alvos militares, as conseqüências de explosões nucleares estendem-se muito além do local do alvo e por muito tempo após a explosão, de modo a causar severos e irreparáveis danos à população civil e ao meio ambiente. Por outro lado, o uso maciço de explosivos nucleares, por uma ou mais das grandes potências, quaisquer que sejam os objetivos, terá conseqüências tão funestas $\mathrm{e}$ catastroficas para a humanidade que sua própria sobrevivência ficará ameaçada.

Diante desta realidade, os cientistas do mundo inteiro não se podem furtar à responsabilidade de assumir posições firmes e definidas contra quaisquer tentativas de expansão da corrida armamentista e a favor de medidas que conduzam a uma redução dos arsenais nucleares e da ameaça de uma conflagração nuclear. Devemos empenhar nossos esforços no sentido de que sejam banidos, por consenso universal, o uso, a fabricação e o armazenamento de armas nucleares, assim como já foi banido, por comum acordo entre as naçōes, o uso da guerra bacteriológica.

Instituiçōes especificamente

(...) a descoberta dos armamentos nucleares introduz uma mudança qualitativa no equacionamento do problema da convivência entre naçōes e da resoluçāo de conflitos pelas armas.
Em particular, há uma crescente preocupação nos meios científicos quanto à utilização de recentes progressos científicos e tecnológicos (por exemplo, lasers) com a finalidade de proporcionar aperfeiçoamentos qualitativos em sistemas armamentícios de tal monta, que possam desencadear um sério desequilíbrio de poder (por exemplo, a "Strategic Defense Initiative") e um recrudescimento da corrida armamentista.

\section{Impacto do avanço tecnológico e industrial no meio ambiente}

As descobertas da físsão e, posteriormente, da fusâo nuclear são exemplos característicos de desenvolvimento científico com profunda repercussão social e impacto sobre o meio ambiente. Além de sua utilização para fins militares, da qual ja falei, elas proporcionam uma nova fonte de produção de energia para fins pacíficos e humanitários, que, principalmente com referência à fusão nuclear, é potencialmente de imensa valia.

Entretanto, a implementação da tecnologia nuclear envolve sérios riscos e problemas que não estão ainda satisfatoriamente resolvidos. No planejamento e funcionamento de usinas nucleares, o fator segurança deve merecer absoluta prioridade. Isto porque, de um acidente num reator nuclear, pode resultar extensa contaminação de águas fluviais ou liberação e propagação na atmosfera de isótopos radioativos de vida longa, que podem causar grandes danos à população das áreas atingidas. Os acidentes no reator nuclear de Chernobil, na Uniāo Soviética, e com o reator de Three Mile Island, nos Estados Unidos, são evidências desse perigo.

Outra consideração importante no aproveitamento da energia nuclear é a questão da disposição do chamado lixo nuclear, isto é, dos isótopos radioativos de vida muito longa produzidos no processo de fissão do combustível nuclear.

Estas questões, é claro, têm sido objeto de intensos estudos e debates. 
Não sou um especialista neste assunto, mas, ao focalizk-lo aqui, meu objetivo e o de chamar atenção para a existência desses problemas e da responsabilidade dos cientistas, sobretudo aqui no Brasil, de alertar e informar objetivamenté a população e os poderes públicos, para que sejam devidamente e criteriosamente considerados quando se inicia a implantação de tecnologia nuclear no País.

O problema da alteração e contaminação do meio ambiente é, porém, .auito mais geral e esta se tornando um efeito cada vez mais nocivo e perigoso do desenvolvimento industrial e tecnológico. A poluiçăo química dos rios, sobretudo nos centros industriais e urbanos, $€$ motivo de grande preocupação por representar ameaça para a qualidade de vida e para o equilíbrio ecol6gico.

No Brasil, parece haver, ainda, pouca regulamentação e controle por parte do setor público a respeito da destruição e poluição do meio ambiente, causada pelo desenvolvimento industrial ou mesmo agrícola. Acho muito importante que sejam feitos maiores investimentos na pesquisa de avaliação e de meios de saneamento de processos e metodos industriais e tecnol6gicos prejudiciais ao meio ambiente.

Além da questão da poluição do meio ambiente, também creio que se deve chamar a atençăo para o uso desmedido e predatório de riquezas naturais e sua eventuais conseqüências. Aqui no Brasil, o problema do desmatamento imoderado e desordenado da floresta amazónica parece a mim merecer atenção especial.

\section{Distribuichao dos benefícios} resultantes do progresso cientifico e tecnolbgico

A terceira questão que propus a respeito do relacionamento entre progressos cientificos e bem-estar social refere-se à distribuição dos beneficios advindos desses progressos, seja entre diversos setores e classes sociais, seja entre países em diferentes estágios de desenvolvimento e industrialização.

Inicialmente, convém indagar se, de fato, o progresso científico tem de um modo geral contribuído para o bem-estar social e de que maneira se dá esta contribuição.

A resposta à primeira pergunta, parece-me ser claramente afirmativa,

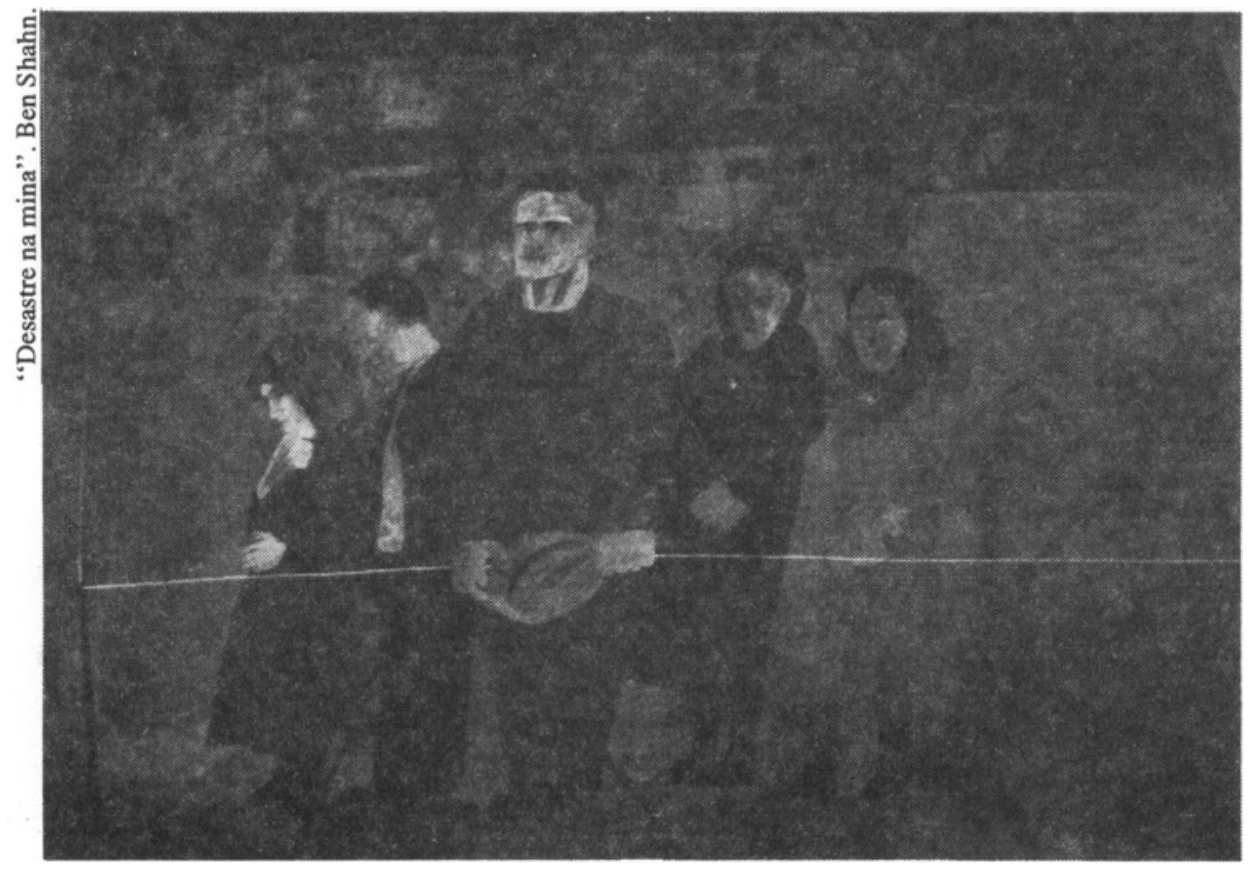


embora possam ser levantadas inúmeras qualificaçōes.

De um modo geral, o progresso tecnol6gico tem permitido aumentar o rendimento do trabalho humano, melhorar as condições de trabalho e substituir o esforço físico do homem ou da mulher pelo trabalho mecânico da máquina.

$\mathrm{Na}$ área da saúde, importantes descobertas permitiram o controle de epidemias através da vacinação, $e$ considerável redução nos índices de mortalidade, sobretudo a partir das descobertas dos antibióticos.

Nos países onde programas de saúde são acessíveis à população, a vida média das pessoas tornou-se bem mais longa.

Os aperfeiçoamentos nos métodos de produção de alimentos, quer seja na agricultura ou na pecuária, têm permitido sustentar populaçōes cada vez mais numerosas.

Este fator, juntamente com uma redução da mortalidade infantil e o controle de epidemias são responsáveis por um crescimento exponencial de população no mundo inteiro e, paradoxalmente, sobretudo nos países menos desenvolvidos.

Por outro lado, há ainda, no mundo de hoje, condições de vida, em muitos países, verdadeiramente subumanas, de extrema miséria, de subnutrição, de incidência endêmica de enfermidades, de altos índices de mortalidade infantil.

Estas condições são encontradas principalmente em países que só recentemente emergiram do colonialismo, ganhando independência política depois da Segunda Guerra Mundial, mas também em quase todo o hemisfério sul, incluindo a maioria dos países da América Latina.

No caso do Brasil, em particular, houve um surto de progresso tecnológico e industrial nos últimos 20 anos, mas, infelizmente, segundo dados estatísticos das Naçōes Unidas, foi em nosso país onde mais se acentuaram a concentração de riqueza $\mathrm{e}$ as diferenças sociais entre aqueles que se beneficiam do progresso e aqueles que vivem à margem dele, não somente sem recursos para participar da economia e beneficiar-se do desenvolvimento do País, mas lutando apenas pela sobrevivência em condiçôes precárias e desumanas.

É claro que se deve esperar que os benefícios derivados do progresso científico sejam principalmente canalizados para os países mais desenvolvidos, que, com maior capacidade técnica e econômica, mais investem na pesquisa científica $e$, conseqüentemente, se mantêm na liderança do progresso tecnológico de fronteira. Além disso, também as necessidades de uma sociedade mais moderna e evoluída são, sem dúvida, maiores e mais discriminativas do que as de uma sociedade num estágio menos avançado de desenvolvimento.

Entretanto, pode-se constatar que, até dentro de uma mesma nação, os benefícios do progresso não são distribuídos de maneira mais ou menos eqüitativa. Em certos casos, esta distribuição torna-se mesmo bastante injusta, com uma grande acumulação de benefícios para pequenos setores sociais, em detrimento da grande maioria da população. Esta distribuição iníqua de recursos tem causado um agravamento de desnível cada vez mais acentuado entre as classes nos níveis mais altos da escala social e as nos níveis mais baixos.

Esta disparidade que, como já mencionei, existe no nosso país, parece ser maior nos chamados países em desenvolvimento ou mesmo em países mais pobres do Terceiro Mundo.

\section{Difusão da ciência e o problema da educação}

Diante desta constatação, creio que devemos refletir sobre como nós, cientistas e universitários em geral, poderíamos contribuir para um progresso que resulte numa distribuição mais eqüitativa de benefícios entre nações e entre vários setores da população. 
Eu penso que $\epsilon$ útil iniciar esta reflexāo procurando discernir em que direção vai, provavelmente, caminhar a ciência, quais áreas de investigação serão dominantes e que impacto social deverá ser esperado.

Em primeiro lugar, considerarei algumas perspectivas na física.

$\mathrm{Na}$ área de física experimental de partículas elementares, as atividades de pesquisa de fronteira têm lugar, como já mencionei, em grandes laboratórios onde se encontram gigantescos aceleradores.

O mais avançado acelerador atualmente em construçăo, o LEP, no CERN, tem por objetivo a produção em grande escala dos mésons vetoriais $\mathbf{Z}$ (partículas mediadoras das interaçōes fracas, cuja existência foi prevista pela Teoria de Calibre unificada das Interaçōes Fracas e Eletromagnéticas). Deverá produzir resultados predominantemente de sistematização, mas também poderá ocorrer alguma nova descoberta que contribua para elucidação de problemas centrais da física de partículas, como, por exemplo, $o$ mecanismo de quebra espontânea de simetria, ou talvez evidência de supersimetria.

A próxima estapa seria o SSC "Superconducting Super Collider", cujo projeto já foi aprovado pelo governo americano. Provavelmente, os europeus, aproveitando as instalaçôes do CERN, construirāo uma máquina semelhante. Esta duplicação de esforços, parece-me desnecessária. Em virtude do custo excessivamente alto de construção e funcionamento de tais aceleradores, acredito que um único projeto de colaboração internacional seria mais recomendável.

Um projeto deste porte dá origem a um grande número de inovaçōes tecnol6gicas. Não obstante, acredito que se deve avaliar cuidadosamente se o retorno, que deste tipo de investimento pode-se realisticamente esperar, justifica o seu custo e utilização de recursos.

A comunidade científica nos Estados Unidos esta bastante dividida a este respeito. Em particular, os físicos da área de física do estado sólido opõem-se ao projeto, alegando que desviará uma parcela demasiado alta de recursos, com prejuízo para outros projetos talvez mais promissores e menos custosos.

No Brasil, obviamente, nāo se cogita de construção de aceleradores de tal porte. Há, porem, projetos de construção de aceleradores menores, aos quais se aplicam estas considerações de custo-benefício. Além disso, para o sucesso de um projeto dessa natureza é importante que, em primeiro lugar, haja um número suficiente de pessoas treinadas para utilizar efetivamente a máquina e, em segundo lugar, $\epsilon$ recomendável que, na medida do possível, seja usada na sua construção tecnologia propria, mesmo que isso acarrete certo atraso na execução do projeto. Por outro lado, o País pode manter uma atividade de fronteira neste campo através de projetos de colaboração internacional com os grandes laboratórios.

Um projeto desta natureza, ja funcionando com sucesso, é o que foi estabelecido entre o Centro Brasileiro de Pesquisas Físicas, no Rio de Janeiro, e o Fermi National Laboratory, nos Estados Unidos. Outro projeto semelhante está sendo iniciado entre o CERN e as universidades Católica e Federal do Rio de Janeiro. Este projeto, aliás, tem, além do mais, o atrativo de envolver uma colaboração Brasil-Portugal, pois a nossa participação será feita através do grupo português com acesso ao CERN, em virtude da condição de país-membro, recentemente conferida a Portugal.

A colaboração internacional em projetos de pesquisa científica, que está sendo, cada vez mais, promovida na Europa, deve servir de exemplo e paradigma para nós, aqui, na América Latina. Este exemplo europeu sugere que maior colaboração e integração entre os países da América Latina, quer no plano econômico, quer no plano cultural, seria muito benéfica 
para o nosso desenvolvimento. $\mathrm{Na}$ área da física, há já em funcionamento o Centro Latino-Americano de Física (CLAF), cuja finalidade principal tem sido de concessão de bolsas de pós-graduação e de estágios de pesquisadores. Instituiçôes como esta devem ser incentivadas e dinamizadas. Porém, podemos ir mais adiante e estudar a possibilidade de criação de centros de pesquisas

latino-americanos.

A física do estado sólido e da matéria condensada é uma área em que tem havido importantes descobertas e que vem progredindo muito rapidamente. Um fenômeno novo importante foi recentemente descoberto, a supercondutividade a altas temperaturas, cujos fundamentos teóricos não são ainda conhecidos e que possivelmente terá inúmeras aplicaçōes práticas.

Em física aplicada, setores que julgo da maior relevância são os de ótica de lasers, energia solar e semicondutores e microeletrônica. Neste último, tem havido um desenvolvimento muito rápido, do qual resultou uma verdadeira revolução no campo das comunicaçōes e da informática. $O$ uso generalizado de computadores e servomecanismos tem conseqüências sociais bastante radicais. O mercado de trabalho é grandemente afetado e continuará sendo cada vez mais alterado por inovaçōes no terreno da informática. Haverá uma grande necessidade de treinamento de pessoal de modo a capacitá-lo a atuar nesta área.

Nas ciências biológicas, antecipa-se um grande progresso na biologia molecular. A descoberta da estrutura molecular do DNA, que possibilitou a compreensão do código genético, serviu de ponto de partida para introdução, em biologia, de novos métodos cujas conseqüências, sobretudo no campo da genética, podem ser tão profundas que suscitem sérias questōes de ética e de regulamentação de seu uso. Por outro lado, abrem-se excelentes perspectivas para utilização de engenharia genética, sobretudo em produção agrícola.

Todas estas conquistas científicas irão tendo suas aplicaçōes na sociedade, acarretando forçosamente grandes mudanças. Embora potencialmente benéficas, pode, todavia, ocorrer que estas conquistas tornem-se até veículo de maior desequilíbrio social ao invés de proporcionarem maior bem-estar para todos. Isto é o que devemos tentar prevenir e evitar.

A meu ver, o que mais necessitamos para chegar a uma distribuição mais eqüitativa dos benefícios do progresso

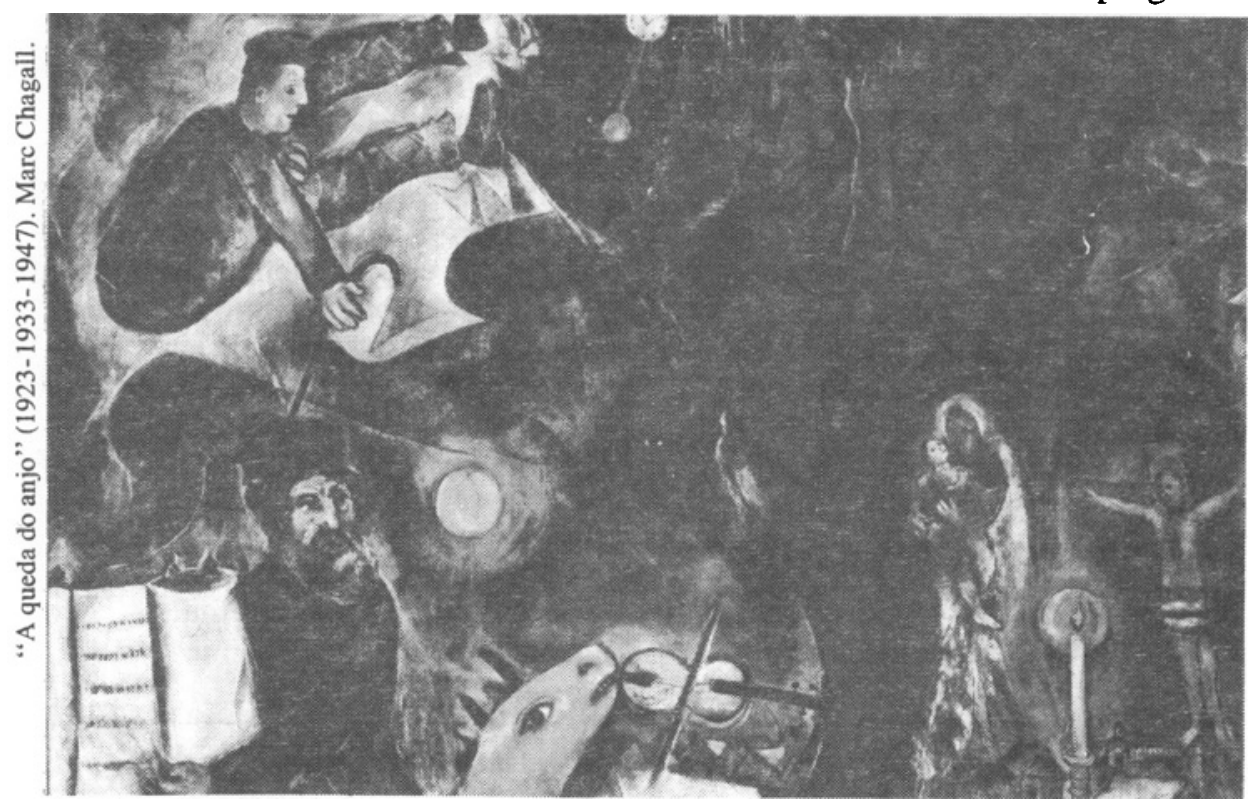


e de um investimento maciço em educação.

Educaçầo, em todos os níveis, mas principalmente nos níveis básicos.

Tem-se argüido que, para tirar o País do atraso é dependência tecnologica

em que se encontra, $\epsilon$ necessário investir mais no ensino superior e na pesquisa cientifica. Concordo com esses argumentos, mas acho que, para conseguir um desenvolvimento mais harmonioso e justo, $\epsilon$ ainda mais necessário investir na educação de base e no aprendizado tecnico.

Nas nossas universidades, constatamos que os estudantes chegam a elas muito despreparados em virtude das deficiências do ensino primário e secundário. Para corrigir essas deficiências, é preciso melhorar sensivelmente a qualidade dos professores de ensino médio, principalmente nas áreas de ciência.

Para atrair e manter bons professores no ensino médio e técnico, os salários nestes niveis devem ser mais compensadores; necessitamos tambem de um número maior de escolas para formação de professores para o ensino médio e de escolas técnicas profissionalizantes.

Especificamente, com respeito ao ensino científico, sugiro que se dê maior difusão da ciência, usando meios de comunicação, como a televisão, em programas de divulgação científica, visando despertar em jovens e crianças a curiosidade pela investigação da natureza $e$ interesse pela ciência.

No Brasil atual, aqueles que chegam ao nível de educação universitária constituem uma pequena minoria que, sem dúvida, se encontra numa situação de privilégio. Por isso, $€$ nossa responsabilidade promover a ascensão daquela maioria que não tem nem a oportunidade do benefício de uma educação secundária e, em certas regióes do País, até mesmo primária.

Paralelamente, há que considerar a situação da saúde pública no País.
Neste setor, as universidades podem e devem desempenhar uma função de liderança. Para isso, deve ser dada prioridade à criação de boas escolas de saúde pública e enfermagem e devem ser incentivados programas de pesquisa em áreas que mais afetam a nossa população como sejam doenças tropicais, endemias rurais etc.

Para que o Pars atinja um nível de modernidade com participação ampla da população, precisamos erradicar completamente $o$ analfabetismo, a subnutrição e a ignorância, de modo que as pessoas possam ter melhores condiçōes de acesso a um mercado de trabalho que exigirá, cada vez mais, novas aptidōes e competências.

Somente através da educaçăo poderemos tirar da marginalidade grandes setores da população e prepara-los para que se tornem mais produtivos, participanres e beneficiários do desenvolvimento do País.

Naturalmente, estes problemas requerem soluçōes políticas. É preciso, portanto, que os políticos estejam bem-informados sobre a posição dos homens de ciência. As sociedades científicas, como a Sociedade Brasileira para o Progresso da Ciência (SBPC), e as associaçōes de classe devem promover 0 debate a respeito desses temas e tomar a liderança para esclarecer a opinião pública e os governantes sobre essas questões que discuti acima e que são especialmente relevantes para 0 desenvolvimento social. Estas sociedades, como a SBPC, que, aliás, no Brasil já estão desempenhando esta função, e sobretudo as universidades, devem estar preparadas para assessorar o poder público em matéria de política científica e exercer influência para que estes princípios de aplicação dos conhecimentos e progressos científicos ao bem comum de toda a sociedade norteiem a ação política e sejam efetivamente implementados.

Samuel MacDowell e físico, professor da Universidade de Yale (EUA) e professor-visitante do IEA em 1988. 